\title{
Editorial
}

\section{Marketing metrics: A can of worms or the path to enlightenment?}

\section{BACKGROUND}

Everywhere you care to look, marketers are talking about metrics. The professional press - Marketing, Marketing News, Professional Marketing etc - is full of articles extolling the importance of metrics. Conferences and workshops question 'Does marketing measure up?' and invite us to contemplate 'The new era of accountable marketing'. The influential Marketing Science Institute (MSI) lists 'metrics' as a top-tier priority topic, ${ }^{1}$ and earlier MSI-sponsored work gave rise to a special issue of the Journal of Marketing. ${ }^{2}$ As a matter of practice, multinationals such as Ford, Henkel, Procter \& Gamble, Kraft Foods, Hewlett-Packard and IBM are saying that marketing measures of success need to be linked explicitly to financial measures (company value, profits, even share/stock performance). Similar messages are now being taken on board by regional and local companies, not just the multinationals. There is a consensus across the professional and corporate world that marketing metrics matter, and that marketers need to smarten up their act.

\section{A CAN OF WORMS?}

On closer inspection, however, this consensus on marketing metrics looks to be more apparent than real. There are three major reasons for suspecting this. First, there is agreement that marketing metrics matter, but no agreement about what they are, except at a very superficial level. So, in all likelihood, when marketers agree, they are probably agreeing to very different things. Secondly, the motives for putting metrics so high up on the marketing agenda are very mixed and possibly confused. Once again, the implication is that when we dig below the surface there may be very little real agreement. Thirdly, measurement difficulties abound, making consensus at an operational level very hard to achieve.

\section{Definitions}

Consider the problem of specifying what marketing metrics are. We could say they are 'the measurement of the effects of marketing activities'. This has the merit of simplicity, but it doesn't progress the discussion much because marketing activities take place at very different levels.

At one level are metrics for gauging the effectiveness of specific programmes and activities, such as the effectiveness of an online advertising campaign, or a loyalty scheme, or a direct-mail promotion. Thus, if we spend more on advertising, do we see a rise in brand awareness, advertising awareness and sales? A simple sales-response model might be used to summarise this effect. Formal modelling of the effectiveness of specific programmes and activities can be traced back 40 years to work 
published in the 1960s. Influential, too, have been various effectiveness awards - EFFIEs in the USA and Europe, IPA awards in the UK, and AFA awards in Australia. With the growth of directresponse advertising, direct marketing and interactive electronic communications, it is now much easier to see whether there is a link between investment in certain specific programmes and a change in sales.

At another level are product- and service-level metrics - these are concerned with brand health and customer satisfaction, and include brand audits and customer-focused measures. Using consumer panel data, brand audits have been undertaken in many packaged goods markets for 50 years or so (resulting in measures of sales, penetration, repeat buying, share of category requirements etc). ${ }^{3}$ Recent interest in metrics at this level has been stimulated by brand equity studies — with close attention being paid to measures of brand perception, familiarity and availability.

A third level concerns metrics that link general investments in marketing and marketing-related activities to overall measures of corporate or strategic business unit (SBU) performance. For example, can a company that has processes in place to sense market opportunities and fulfill customer needs demonstrate superior performance (sales, margins, profits, shareholder value etc)? Furthermore, to what extent does business performance (in terms of financial measures) depend on marketing investments, innovation, entrepreneurship and organisational learning? We say that these relationships exist, but only with appropriate metrics can they be demonstrated. This interest by marketers in making links to business/financial measures is matched by the interest of accountants in market/customer issues (eg market shares), internal processes (eg percentage sales from new products) and organisational learning (eg employee turnover), with the 'balanced scorecard' being the most evident sign of this interest. ${ }^{4}$

\section{Motives}

The second problem is that motives for placing metrics so high up on the marketing agenda are extremely mixed. Some motives are very positive, if not inspirational. Here, for instance, is the viewpoint of the Australian Marketing Institute (AMI): 'Leading marketers point out that while selling may be about creating cash flow now, marketing is more about creating future cash flows, and a powerful brand is like a reservoir of that future cash flow. If this is true, then it is very important to have measures, or metrics, that help us manage and maintain brands and maintain marketing strength. ${ }^{5}$ But other motives are questionable and potentially unhealthy. In general, three sets of motive can be identified:

First, marketing-specific reasons: such as to assist in the process of resource allocation (eg whether to invest scarce marketing resources in traditional media advertising or web-based communications). Also, to help organisations learn and understand more about their business (to know which controllable elements of the business are responsible for financial outcomes), their customers (to know who are the most profitable customers, and their markets (to appreciate who are the key competitors). This sees marketing as a research-driven activity, based around 
the marshalling of information.

Secondly, general management reasons: most of these reasons boil down to making marketing more accountable. The logic is simple: marketing is seen as generating a stream of revenue (through sales), and therefore it should be possible to pay for marketing activities by their results. By finetuning activities, it should be possible to obtain more revenue for the same level of investment: more bang for the bucks. A worry among marketers, however, is that the real motives here may be less virtuous. The real goal may be to control costs and achieve efficiency savings (ie less marketing), as distinct from improving effectiveness (ie more effective marketing).

Thirdly, politicking and posturing: are also important drivers behind the use of marketing metrics. Metrics can be used to support a special plea (that one form of activity, advertising say, is more deserving of additional resources than another), or to impress other managers (to gain respect at the boardroom table), or as part of a process of 'making the numbers' within the context of a procedurally based, marketing planning exercise (that is, metrics are presented merely for the sake of appearances). Some of these motives are quite dubious (eg the goal of trying to impress CEOs and CFOs smacks of an unhealthy and unwarranted inferiority complex). But it would be naïve to believe a measurement system could be totally free from such politicking and posturing.

\section{Measurement}

No discussion of metrics can be decoupled from the problem of measurement, especially if we are to move beyond rhetoric and consider practical, operational and usable procedures. In this regard there are a number of problems, as described in the following paragraphs.

The basic decision of which key metrics to use is a matter of contention. Brand-level analysis would suggest a list that includes market share, penetration, repeat buying, brand awareness, relative price and customer satisfaction, but does it also extend to customer complaints and relative product quality? Are we thinking of volumebased market share or value-based market share?

The problem is doubly difficult because many candidate measures are imprecise - they rely on perceptions, impressions, recollections, estimates and forecasts. Do we give as much weight (or even more weight) to perceptual measures (eg perceived relative price) as we do to concrete measures (eg actual relative price)? Answers are not easy to agree, but whatever answers are agreed, the inherent imprecision of our methods must be acknowledged and users protected against drawing false and misleading inferences.

There is also the question of whether metrics should be grouped into composite measures or indexes. Usual commercial practice is to work with distinct, ungrouped measures (eg a manager interested in customer loyalty/retention might look at share of category requirements, duplicate buying and repeat buying, but will not group these into a composite measure). Many academics, by contrast, argue for composite measures that capture the essence of underlying (latent) constructs. Whichever path is chosen, it is clear that any measurement procedure 
raises questions about construct validity and reliability.

Any use of metrics in the assessment of marketing activities and investments raises standard modelling and forecasting issues: the effect of leaving out important variables from our model (omitted variables), problems arising from seasonal factors (especially with sales data) and the degradation of the signal-to-noise ratio as the analytical time horizon is increased (eg is that projected increase in sales a result of our advertising campaign? or the failure of our competitor's advertising campaign? or an increase in product availability? or an upturn in the economy? - it gets harder to tell as we look further and further into the future).

Wherever possible, measures should be related to a benchmark or norm, or expressed relative to a competing alternative. A typical problem is whether the sales success of a brand arises from creative advertising or sheer weight of advertising spend - it is tough addressing this problem without knowing the expenditure on advertising by competitors. Yet, even in this information-rich world, reliable data about a competitor's marketing investments and business performance may be quite poor (except for top-level indicators such as share/stock performance).

\section{THE PATH TO ENLIGHTENMENT?}

The discussion above shows there are many challenging and problematic aspects to the use of marketing metrics. But it would be wrong to decry or abandon marketing metrics out of frustration, merely seeing it as a difficult can of worms. Instead, we should try to tease out the beneficial aspects, while being alert to the problems. This begins with some very basic steps, especially in the area of training. It means building on our existing capabilities to develop and refine our metrics, all the while, making sure the unique character of marketing is fully exploited. This will set us on the path to enlightenment.

\section{Training}

A three-fold approach is needed in the area of training:

First, improve the analytical skills of marketers. Many marketers already have well-honed analytical skills (eg the type of skills to be found in specialist consultancies and research agencies), but this cannot be said of them all. This is not only about marketers being able to understand numbers and make measurements, but - more importantly - being able to interpret what the numbers say and to draw meaningful insights. It also means having a healthy understanding of the strengths and limitations of numbers, measures and analyses (such as the use of benchmarks and the problems of omitted variables).

Secondly, increase levels of financial literacy among marketers. At an elementary level, most marketers can read a financial statement, but many can do little more than this. It is rare to see a financial glossary in marketing textbooks although it is not unreasonable to expect marketers to understand and use terms such as discounted cash flow (DCF) and net present value (NPV). (Exceptions include: Doyle; Bannock et al.; and other standard business dictionaries. ${ }^{6}$ ) Marketers need to be cognisant of financial outcomes, and not merely 
think in terms of awareness and satisfaction measures.

Thirdly, increase levels of marketing literacy among financial accountants, CFOs and CEOs. Financial managers need to appreciate that marketers are more interested in customers than in investors, are more interested in consumer markets than capital markets, are more interested in revenue generation than cost control, and that there is good reason for everyone in the organisation to pay more attention to these facets of business. This requires financial managers to be more aware of the importance of metrics suited to the analysis of customers, consumer markets and generation of revenue (eg repeat buying and market share, relative price, product availability, perceived product quality, customer satisfaction, loyalty/retention, complaints, awareness and familiarity). This requires a change in the information that is being presented to main boards (which, not surprisingly, is quite a challenge and one that not everyone is confident of marketers being able to achieve $^{7}$ ).

\section{Metrics}

Metrics themselves require our attention:

Codify the metrics that exist: a considerable number of candidate metrics are to hand. It is not as if we have to invent a whole new toolkit. What we do not have is a single 'best' measure, nor are we ever likely to have one. But, rather than look for elusive magic bullets, a more productive task is to appraise the metrics we have and, where necessary, refine them (recognising that they are not all equally useful, reliable or valid). (A major statement of what is known is provided by Rust et al. ${ }^{8}$ )

Agree different metrics for different levels of analysis and engagement: the AMI draws a useful distinction between key metrics that reflect a company's strategic positioning (eg financial metrics, general brand equity metrics, innovation metrics and employeebased metrics) and operational metrics (eg new product development prelaunch, new product development post-launch etc). ${ }^{9}$ The former are general, strategic metrics of the type we would expect to be discussed at main board level, whereas the latter are critically important to those working in the functional divisions of marketing, but are not necessarily going to find their way into the discourse at main board level.

Agree different metrics for different purposes: once again the AMI report provides helpful examples; for instance, a contrast can be drawn between sales promotion metrics (sales uplift from the promotion, cost per promotion, coupon redemption rate, channel/vendor participation and number of promotions conducted) and loyalty programme metrics (participation, customer satisfaction, relative purchase frequency, programme cost and relative purchase volume). ${ }^{10}$ One size does not fit all.

\section{Non-metrics}

Marketing is not a branch of financial accounting. So, the final set of issues on the path to enlightenment relate to the unique and distinct characteristics of marketing:

Ways must be found for metrics to sit comfortably beside the creative aspects of marketing. While it is important to 
improve analytical skills — specifically, quantitative analytical skills - one of the unique characteristics of marketing is the emphasis given to creativity. Sales might rise not because we spend more than our competitors, but because we have superior insight into the minds and actions of customers, or because we display more imagination in the execution of our marketing communications. These aspects of marketing are hard to quantify and formalise, yet the commercial benefits are real enough — creative successes certainly have the potential to have an impact on sales and make a difference to the bottom line.

Metrics are needed that encourage and nurture innovation and enterprise. This means being alert to the danger that a myopic obsession with metrics can lead to an overly cautious approach ('analysis paralysis'). Whereas part of our contribution to business is to be the risk takers - to propose new and different ways of meeting the needs, wants and desires of customers, to innovate and experiment, and to be entrepreneurial in our approach.

The people skills required of marketers must be acknowledged and appropriately factored into our considerations. Metrics, however important they might appear, do not make sales or negotiate deals. People make sales. People negotiate. While the outputs of sales, service encounters and negotiations are reasonably easy to measure, the human inputs are not so easily measured. How do we fully capture passion, commitment, relationship building, a sense of timing, brinkmanship and all the other 'touchy-feely' aspects of marketing? The danger is that things that are not easily measured are ignored or sidelined ('what isn't measured doesn't get done'), which is very different from saying they are unimportant.

If, as a result of a new-found focus on marketing metrics, there is a sidelining of creativity, innovation and people skills, marketing would surely have lost its way. As Peter Wells of nilewide has written: 'over the past few years many commentators have suggested that marketing is suffering from a loss of innovation and creativity. These claims come at a time when we have more metrics than ever to assess effectiveness ... our current metrics measure only the rational while the people who buy our products and services are rational, emotional, spiritual and political beings. ${ }^{11}$

The message is not as simple as it first appeared from the bold and ambitious statements seen in the professional press and from the rallying cries of advocates at the MSI, American Marketing Association (AMA), AMI etc. There are difficulties in defining what is meant by marketing metrics, in deciding appropriate levels of analysis and in using the measures. Nevertheless, this should not be read as a call to decry or abandon metrics. To take an analogy - we do not abandon accounting simply because there are differences of opinion over the use of historical cost accounting, inflation accounting and fair value. Instead, standards and conventions are agreed and observed until such time as newer standards are put in place. The challenge for marketers is whether similar standards can be agreed and observed, without a loss in creativity, innovativeness and people skills. Looking at the situation optimistically, perhaps we can say that because marketers appreciate the things that cannot be measured so easily, as well as those that can, they are better placed than most to add value to 
the customers they serve and to the companies for which they work.

\section{Mark Uncles Editorial Board}

\section{References}

(1) MSI (2004) '2004-2006 Research Priorities', Marketing Science Institute, Cambridge, MA, available at http://www.msi.org.

(2) Lehmann, D. R. (2004) 'Metrics for making marketing matter', Journal of Marketing, Vol. 68, No. 4, pp. 73-75.

(3) Ehrenberg, A. S. C., Uncles, M. D. and Goodhardt, G. J. (2004) 'Understanding brand performance measures: Using Dirichlet benchmarks', Journal of Business Research, Vol. 57, No. 12, pp. 1307-1325.

(4) Kaplan, R. S. and Norton, D. P. (1996) 'The Balanced Scorecard: Translating Strategy into Action', HBS Press, Boston, MA; Kaplan, R. S. and Norton, D. P. (2004) 'Strategic Maps: Converting Intangible Assets into Tangible Outcomes', Harvard Business School Publishing, Boston, MA.

(5) AMI (2004) 'What value marketing? A position paper on marketing metrics in Australia', Australian Marketing Institute, Sydney, p. 1, available at http://www.ami.org.au.

(6) Doyle, P. (2000) 'Value Based Marketing', Wiley, London, UK; Bannock, G., Davis, E., Trott, P. and Uncles, M. (2002) 'The New Penguin Dictionary of Business', Penguin Books, London, UK.

(7) Ambler, T. (2003) 'Marketing and The Bottom Line: Health Drives Wealth', 2nd edn, Prentice Hall/Financial Times, London, UK.

(8) Rust, R. T., Ambler, T., Carpenter, G. S., Kumar, V. and Srivastava, R. K. (2004) 'Measuring marketing productivity: Current knowledge and future directions', Journal of Marketing, Vol. 68, No. 4, pp. 76-89.

(9) AMI, ref. 5 above, p. 59.

(10) Ibid.; Uncles, M. D., Dowling, G. and Hammond, K. (2002) 'Customer loyalty and customer loyalty programs', Journal of Consumer Marketing, Vol. 20, No. 4, pp. 294-316 (especially Section 6).

(11) Wells, P. (2001) 'Irrational rational', Vol. 11, No. 6, 24th February, available at http://www.nilewide.com; nilewide (2005) 'Measured, but not read?', Vol. 19, No. 10, 3rd April, available at http://www.nilewide.com. 